\title{
Hepatite fulminante na Amazônia brasileira
}

\author{
Hepatitis fulminant in Brazilian Amazon
}

José Carlos Ferraz da Fonseca ${ }^{1}$

\begin{abstract}
RESUM0
O autor faz uma revisão e atualização sobre os resultados das pesquisas envolvendo a hepatite de Lábrea e outras hepatites fulminantes da Amazônia ocidental brasileira, com ênfase nas características epidemiológicas, clínicas e histopatológicas e na etiologia viral, como os vírus das hepatites B e D. 0 potencial envolvimento de alguns outros vírus hepatotrópicos é considerado.
\end{abstract}

Palavras-chaves: Hepatite B. Hepatite D. Amazônia.

\begin{abstract}
The author makes a revision and an update on the results of the researches involving the Labrea hepatitis and others fulminant hepatitis in western Brazilian Amazon, with emphasis in the clinical, epidemiologic, histopatologic characteristics and viral etiology as hepatitis B and D viruses. Potential etiologic role of same anothers hepatotropic virus is considered.
\end{abstract}

Key-words: Hepatitis B. Hepatitis D. Amazon.

Na região Amazônica ocidental brasileira, em especial no Estado do Amazonas, especificamente na calha do Rio Purus, uma forma atípica de hepatite fulminante já se fazia presente há mais de 60 anos, embora somente descrita em $1985^{8}$. 0 primeiro registro leigo da doença estaria contido no Livro de Tombo da Prelazia de Lábrea em maio de $1963^{19}$. Durante nossos estudos científicos em busca dos conhecimentos desta entidade nosológica, no início da década de 80, ouvimos atentos dos mais idosos habitantes das calhas dos Rios Purus, Solimões e Juruá que tal doença dizimava famílias inteiras nas vilas, povoados e seringais, principalmente na fase do boom da borracha, fim do século XIX e início do século XX. De acordo com estes relatos, as principais vítimas foram principalmente os chamados soldados da borracha e familiares, constituídos na maioria de imigrantes nordestinos. A doença começava abruptamente, 0 paciente tinha falta de paciência, tristeza e permanecia o tempo todo calado. Em torno de 24 horas, o paciente agitava-se, falando palavras desconexas e de baixo calão, quebrando tudo ao seu redor, mordendo as pessoas, chegando a vomitar o fígado. Após tal quadro, o paciente entrava em coma profundo e, geralmente após 72 horas do início da doença, morria. Talvez 0 relato mais interessante seria que, após a morte, 0 defunto continuava quente por mais de seis horas e sangrando pelo nariz.

Em 1966, de acordo com Santos ${ }^{19}$, o primeiro informe e registro científico sobre tal entidade foi relatada por Leite e cols, sendo denominada pelos autores de doença de Lábrea. Tal estudo revelou um quadro histopatológico diferente da forma clássica de hepatite fulminante, com uma grave atrofia hepática do tipo agudo ou subagudo, com necrose hialina, degeneração gorda e hidrópica, com figuração típica de células em aranha, posteriormente chamada pelos autores brasileiros de células em mórula ${ }^{9}$.

Em decorrência do primeiro registro leigo e científico desta entidade ter sido no município de Lábrea (Estado do Amazonas, Brasil), tal forma de hepatite grave receberia cientificamente diversas denominações, tais como febre da Amazônia, febre negra do Rio Purus, de Lábrea, hepatite de Lábrea, hepatite fulminante de Lábrea, febre Negra, febre negra de Lábrea. Doravante, passaremos a descrevê-la somente como hepatite fulminante de Lábrea.

Entre as décadas de 60 e 70, diversos trabalhos publicados revelaram as peculiaridades clínicas desta forma de hepatite fulminante ${ }^{679}$. Tal entidade seria uma forma grave e evolutiva de hepatite, acometendo principalmente crianças e adultos jovens, caracterizada por sintomas digestivos hemorrágicos (hematêmese), neurológicos (agitação psicomotora, coma) e com evolução rápida para 0 óbito. Naquele momento, os autores sugeriam que tal nosologia poderia estar relacionada com um agente viral desconhecido e de alta virulência ${ }^{679}$. Em trabalho pioneiro, Bensabath \& Boshel, 1973, detectaram pela primeira

1. Universidade Federal do Amazonas da Fundação de Medicina Tropical, Manaus, AM.

Endereço para correspondência: Dr. José Carlos Ferraz da Fonseca. Gerência de Virologia da Fundação de Medicina Tropical de Manaus. Av. Pedro Teixeira 25, Planalto, 69040-000 Manaus, AM, Brasil.

e-mail: fonseca@prodamnet.com.br 
vez a presença sorológica do então chamado Antígeno Austrália (AU) em um paciente que veio a falecer de hepatite fulminante de Lábrea. Neste mesmo estudo, considerado por nós como pioneiro e de alto valor científico, os autores chamam a atenção pela primeira vez para a alta prevalência do vírus da hepatite B em populações ribeirinhas do Rio Purus, caracterizando tal região como endêmica de infecção por este agente viral ${ }^{1}$.

Em 1978, Santos ${ }^{19}$, estudando o comportamento clínico, epidemiológico e histopatológico da hepatite fulminante de Lábrea, revelou dados que puderam esclarecer em grande parte a história natural da doença ${ }^{19}$. Contudo, os estudos realizados naquele momento não permitiram que 0 autor pudesse admitir qualquer hipótese a respeito da etiopatogênese desta forma atípica de hepatite fulminante ${ }^{19}$. Do ano de 1978 até 1983 , várias hipóteses foram aventadas com relação aos fatores etiológicos da hepatite fulminante de Lábrea, citando, como exemplo, arbovírus desconhecidos, vírus hepatotrópicos desconhecidos, fatores tóxicos como as aflatoxinas, e plantas ( Derris negrensis), conhecida vulgarmente como timbó1679192021.

Em 1983, duas publicações científicas sugeriram a participação do vírus da hepatite (VHB) na etiopatogenia da hepatite fulminante de Lábrea ${ }^{213}$. De acordo com uma destas publicações ${ }^{13}$, os autores chamam a atenção para dois fatos importantes: 0 primeiro epidemiológico, ou seja, a ocorrência desta patologia em outras áreas da Amazônia, como no município de Codajás, rio Solimões; 0 outro, com relação aos aspectos evolutivos não sendo encontrada pelos autores quaisquer diferenças que pudessem distinguir clinicamente em entidades separadas a hepatite fulminante de Lábrea da forma clássica de hepatite fulminante, e sim somente através dos estudos histopatológicos.

Após 1983, estudos soroepidemiológicos com relação à infecção pelo VHB e vírus da hepatite D (VHD) na Amazônia Ocidental revelaram dados preocupantes ${ }^{16}$. Consoante estes estudos, nossa região teria uma das maiores prevalências de infecção pelo VHB e VHD no mundo, sendo considerada pelos autores como uma área de alta endemicidade ${ }^{16}$. Em 1985, um novo estudo sobre a etiopatogenia da hepatite de Lábrea revelou pela primeira vez a presença simultânea dos antígenos do VHB (HBsAg) e do VHD (HDAg) no tecido hepático de pacientes com quadro histopatológico de hepatite fulminante de Lábrea, sugerindo os autores que a etiopatogenia de tal entidade poderia estar relacionada com a coinfecção aguda pelo VHB+VHD ou pela superinfecção pelo VHD em portadores crônicos do $\mathrm{VHB}^{15}$. Posteriormente, a tal publicação, Bensabath e cols ${ }^{3}$, confirmaram tais achados, sugerindo ainda os autores que as células em mórula, achado histopatológico clássico da hepatite fulminante de Lábrea, seriam patognomônicas da superinfecção VHD em portadores do HBsAg e que provavelmente outros agentes virais hepatotrópicos estariam envolvidos em sua etiopatogenia ${ }^{3}$. Em diversas regiões do mundo, uma forma fulminante de hepatite com aspectos clínicos e achados histopatológicos ( células em mórula) similares a hepatite fulminante de Lábrea foi relatada na África Central ${ }^{18}$, Colômbia ${ }^{4}$, Peru ${ }^{5}$ e Venezuela ${ }^{17}$, sendo a infecção pelo VHD incriminada como principal fator etiopatogênico.

Durante um certo período de tempo, acreditava-se que a etiopatogenia da hepatite fulminante de Lábrea estivesse estritamente ligada à infecção pelo VHD. Porém, em 1992, um novo estudo revelou a participação efetiva de outros vírus hepatotrópicos nesta entidade ${ }^{11}$. Neste estudo, Fonseca e cols ${ }^{11}$, demonstraram que apenas $36,4 \%$ dos pacientes apresentavam evidência sorológica de infecção aguda pelo VHD e uma grande maioria dos pacientes, ou seja, 63,6\% tinham evidência de infecção aguda pelos VHA, VHB e VHC, com infecção viral isolada, simultânea ou por superinfecção. Independentemente da participação viral, nesta forma de hepatite fulminante, os autores consideram neste trabalho que a etiopatogenia da hepatite fulminante de Lábrea poderia estar associada a fatores genéticos, imunológicos e etários. Finalmente, os autores levantaram a hipótese de que cepas variantes tanto do VHA, VHB, VHC e VHD poderiam determinar mudanças na resposta imune destes pacientes, determinando assim uma severa forma de hepatite. Estudos recentes reforçam tal hipótese, principalmente sobre 0 VHD. De acordo com Caseyetal ${ }^{5}$, a participação única do genótipo III do VHD associada ao subtipo Fdo VHB poderia estar relacionada com as formas gravissimas de hepatite ocorridas durante um surto entre militares peruanos a serviço na Bacia Amazônica Peruana.

Posteriormente a 1992, diversos informes científicos referentes ao tema foram publicados ${ }^{10} 12$, e, de acordo com a dimensão destes resultados encontrados, poderíamos admitir as seguintes conclusões sobre a hepatite fulminante na Amazônia brasileira: 1) não existem parâmetros epidemiológicos (demográficos), clínicos, laboratoriais e etiológicos que possam diferenciar uma hepatite fulminante clássica, sem o substrato histológico de células em mórula, de uma hepatite fulminante com células em mórula; 2) a única diferença estaria neste substrato patológico, ou seja, um determinado número de pacientes apresentaria um quadro histológico típico, no qual observa-se uma forma confluente de necrose lítica com esteatose microvesicular (células em mórula); 3) em nossa região, existem dois padrões histopatológicos distintos de hepatite fulminante: um padrão de hepatite fulminante com células em mórula e 0 outro padrão sem células em mórula; 4) 0 termo hepatite fulminante de Lábrea deve ser lembrado, descrito e narrado apenas como um fato histórico; 5) a utilização de testes biológicos moleculares de última geração permitiramnos identificar em $98 \%$ dos casos os fatores etiopatogênicos das formas fulminantes de hepatite em nossa região; 6) a coinfecção aguda viral ou superinfecção, observada freqüentemente entre pacientes com hepatite fulminante na Amazônia brasileira, é um indicativo de incrível risco para o desenvolvimento de formas graves de hepatite, com altas taxas de óbito, em torno de 95\%; 7) finalmente, poderíamos admitir que a presença das células em mórula nas formas fulminantes de hepatite, observadas em nossa região, possa estar relacionada a um grande e severo bloqueio da função das células hepáticas, que poderia estar condicionado a um efeito mediado pela resposta imunecelular do hospedeiro ou através de um efeito citopático viral.

\section{REFERÊNCIAS BIBLIOGRÁFICAS}

1. Bensabath $\mathrm{G}$, Boshell J. Presença do antígeno de Austrália em população do interior do Estado do Amazonas. Revista do Instituto de Medicina tropical de São Paulo 15: 284-288, 1973. 
2. Bensabath G, Dias LB. Hepatite de Lábrea (Febre Negra de Lábrea) e outras hepatites fulminantes em Sena Madureira, Acre e Boca do Acre, Amazonas, Brasil. Revista do Instituto de Medicina Tropical de São Paulo 25: 182194, 1983.

3. Bensabath G, Hadler SC, Pereira Soares MC, Fields H, Dias LB, Popper H, Maynard JE. Hepatitis Delta virus infection and Labrea hepatitis Prevalence and role fulminant hepatitis in the Amazon basin. Journal of American Medical Association 258:479-483, 1987.

4. Buitrago B, Popper H, Hadler SC, Thung SN, Gerber MA, Purcell RH, Maynard JE. Specific histologic features of Santa Marta Hepatitis: a severe form of hepatitis Delta virus infection in Northern South America. Hepatology 6: 1285-1292, 1986.

5. Casey JL, Niro GA, Engle RE, Veja A, Gomez H, McCarthy, Watts DM, Hyams KC, Gerin JL. Hepatitis B virus ( HBV) hepatitis D. virus (HDV) coinfection in outbreaks of acute hepatitis in the Peruvian Amazon basin: The roles of HDV genotype III and HBV genotype F. Journal of Infection Diseases 174:920-926, 1996

6. Costa EA. Febre negra do Rio Purús. Gazeta Médica da Bahia 3: 148-175, 1970.

7. Dias LB, Moraes MAP. Hepatite de Lábrea. Revista do Instituto de Medicina Tropical de São Paulo 15: 86-93, 1973.

8. Dias LB, Coura JR. Hepatite de Lábrea. Estudo de revisão em viscerotomias hepáticas nos anos de 1934 a 1940. Revista do Instituto de Medicina Tropical de São Paulo 27: 242-248, 1985.

9. De Paola D, Pinheiro AF, Dias LB, Lacerda PRS. A febre da Amazônia. 0 Hospital 71: 130-131, 1967.

10. Fonseca JCF, Brasil LM, Castilho MC, Botelho R, Braga WM, Ferreira LC. Fulminant hepatitis and microvesicular steatosis (morula-like cells). A study in children and adolescents. Hepatology 30:284 A, 1999.

11. Fonseca JCF, Ferreira LCL, Brasil LM, Castilho MC, Moss R, Barone M. Fulminant Labrea hepatitis: Role of HAV, HBV and HDV infection. Revista do Instituto de Medicina Tropical de São Paulo 34: 609-612, 1992.
12. Fonseca JCF, Ferreira LCL, Castilho MC, Brasil LM, Botelho R, Braga WSM Pereira LMMB. Etiopatological aspects of fulminant hepatitis ( $\mathrm{fh}$ ) in the Brazilian Amazon basin. Hepatology 19 ( supl) :62I, 1994.

13. Fonseca JCF, Ferreira LCL, Guerra ALSP, Passos LM, Simonetti JP. Hepatite Fulminante e Febre Negra de Lábrea: Estudo de 5 casos procedentes de Codajás, Amazonas, Brasil. Revista da Sociedade Brasileira de Medicina Tropical 16: 144-147, 1983.

14. Fonseca JCF, Gayotto LCC, Ferreira LCL, Araújo JR, Alecrim WD, Santos RTM, Simonetti JP, Alves VAF. Labrea hepatitis-hepatitis B and Delta antigen expression in liver tissue: report of three autopsy cases. Revista do Instituto de Medicina Tropical de São Paulo 27:224-227, 1985.

15. Fonseca JCF, Simonetti SRR, Schatzmayr HG, Castejón MJ, Cesário ALO, Simonetti JP. Prevalence of infection with hepatitis delta virus (HDV) among carriers of hepatitis B surface antigen in Amazonas State, Brazil. Transaction of the Royal Society of Tropical Medicine and Hygiene 82: 469-471, 1988.

16. Fonseca JCF, Ferreira LCL, Figueiredo LPG, Brasil GD, Castilho MC, Araújo JR. Acute liver failure: morphological patterns and etiological aspects in Amazon basin. Hepatology 28 ( supl) : 494A, 1998.

17. Hadler SC, Monzon M, Ponzetto A, Anzola R, Rivero D, Mandolfi A, Bracho A, Francis DP, Gerber MA, Thung S, Gerin J, Maynard JE, Popper H, Purcell RH. Delta virus infection and severe hepatitis. An epidemic in the Yucpa indians of Venezuela. Annals of Internal Medicine 100: 339-344, 1983.

18. Lesbordes JL, Trepo C, Ravisse P, Chevalier P, BeuzitY, Vohito MD, Meunier DMY, Gonzalez JP, Sepetjan M, Georges AS. Infection with hepatitis Delta virus in Bangui. New England Journal of Medicine 314: 517 -518, 1986.

19. Santos JB. Febre negra na região de Lábrea, AM. Estudo clínico epidemiológico e histopatológico. Tese de Mestrado, Universidade de Brasília, Brasília, 1978.

20. Rodrigues FA, Salles JM, Viana CN, Leitão EG. Febre negra: considerações sobre aspectos clínicos. Revista da Universidade do Pará 1:33-342, 1971.

21. Viana CHM, Odebrecht S, Campelo AP, Dourado HD. Ação tóxica de extratos de Derris negrensis ( timbó) "in vivo" e "in vitro". Arquivos de Biologia e Tecnologia 22: 95-109, 1979 